\title{
Evaluation of immunochromatography tests for detection of novel GII.17 norovirus in stool samples
}

P Khamrin1,2,3, A Thongprachum2,3, S Takanashi2,3, S Okitsu2,3, N Maneekarn1, S Hayakawa3, H Ushijima (ushijima-hiroshi@ jcom.home.ne.jp)2,3

1. Department of Microbiology, Faculty of Medicine, Chiang Mai University, Chiang Mai, Thailand

2. Department of Developmental Medical Sciences, School of International Health, Graduate School of Medicine, The University of Tokyo, Tokyo, Japan

3. Division of Microbiology, Department of Pathology and Microbiology, Nihon University School of Medicine, Tokyo, Japan

Citation style for this article:

Khamrin P, Thongprachum A, Takanashi S, Okitsu S, Maneekarn N, Hayakawa S, Ushijima H. Evaluation of immunochromatography tests for detection of novel Gll.17 norovirus in stool samples. Euro Surveill. 2015;20(28):pii=21185. Available online: http://www.eurosurveillance.org/ViewArticle.aspx?Articleld=21185

A novel GII.17 norovirus has emerged as a major cause of epidemic and endemic acute gastroenteritis in several countries in Asia. We used a small panel of stool samples in which GII.17 virus had been quantified by real-time RT-PCR to evaluate four commercially available norovirus immunochromatography (IC) kits. At least $10^{8}$ copies/mL of GII.17 virus were required by each IC kit for a positive result, which is 1,000-fold more than that reported for these assays for GII.4 viruses.

In the winter of $2014-15$, a novel Gll.17 norovirus variant emerged in several countries in Asia [1]. From September 2014 to March 2015, 70\% of all outbreaks in Guangdong and Jiangsu provinces in China were caused by a novel GII.17 virus [2,3]. A similar increase in the number of infections with this novel GII.17 virus has been reported in Japan [4] and Thailand since December 2014. In this study, we assessed whether current immunochromatography (IC) tests can detect these novel Gll.17 noroviruses.

\section{Laboratory investigation}

For the rapid detection of norovirus, an IC test is one of the most convenient and accessible diagnostic tools commonly used in primary care units and private clinics in Japan [5]. However, these IC tests were developed mainly for the detection of genotypes such as GII.3 and GII.4. To evaluate if these IC tests are able to detect these novel GII.17 noroviruses, we tested four commercial IC kits available in Japan: GE test Noro Nissui, Nissui Pharmaceutical Co., Ltd.; ImmunoCatch-Noro, Eiken Chemical Co., Ltd.; Quick Navi-Noro 2, Denka Seiken Co., Ltd.; Quick Chaser-Noro, Mizuho Medy Co., Ltd.
A panel of six Gll.17-positive stool samples from patients in Japan $(n=5)$ and Thailand $(n=1)$, in which the virus copy numbers had been quantified by realtime RT-PCR (reference values), were randomly selected from stool samples for which there was a large quantity available. Two of the six Gll.17 stool samples tested positive by all four IC kits (Table).

Testing of the six specimens by real-time RT-PCR demonstrated that the two samples that were positive by IC test contained high virus titres $\left(1.90 \times 10^{9}\right.$ and $8.06 \times$ $10^{9}$ virus copies $/ \mathrm{mL}$ ). In contrast, the other four specimens that were negative in the IC test had virus titres ranging from $4.91 \times 10^{3}$ to $2.50 \times 10^{8}$ virus copies $/ \mathrm{mL}$. One of the two specimens positive in the IC tests ( $\mathrm{HU}$ 2015) was re-tested using $1: 10$ and 1:100 stool dilutions, using three of the four kits (one was not available at the time of re-testing). The results demonstrated that at $1: 10$ dilution (virus titre $1.90 \times 10^{8}$ copies $/ \mathrm{mL}$ ) two of three tests still showed the positive results, with a weak positive band, while at 1:100 dilution (virus titre $1.90 \times 10^{7}$ copies $/ \mathrm{mL}$ ), all three IC tests were negative. These data demonstrated that the sensitivity of the IC kits for the detection of this novel GII.17 virus was about $10^{8}$ copies $/ \mathrm{mL}$.

\section{Discussion}

Norovirus is one of the most common etiological agents of acute gastroenteritis in people of all ages in developing and developed countries [6]. The virus is transmitted mainly via food and water and by personto-person. On the basis of sequence differences in the virus VP1 region, noroviruses can be divided into seven genogroups (GI to GVII): viruses from GI, GII and GIV cause disease in humans. GI is further divided into nine genotypes (GI.1 to Gl.9) while Gll contains at least 22 genotypes (GII.1 to Gll.22) [7]. Of all genotypes, 
Virus copy numbers of six GII.17 noroviruses tested and results of four norovirus immunochromatography tests

\begin{tabular}{|c|c|c|c|c|c|c|}
\hline \multirow{2}{*}{$\begin{array}{l}\text { Norovirus } \\
\text { GII.17 } \\
\text { sample ID }\end{array}$} & \multirow{2}{*}{$\begin{array}{l}\text { Date sample } \\
\text { taken }\end{array}$} & \multirow{2}{*}{$\begin{array}{c}\text { Virus titre } \\
\text { (copies } / \mathrm{mL})^{\mathrm{a}}\end{array}$} & \multicolumn{4}{|c|}{ Norovirus immunochromatography tests } \\
\hline & & & ImmunoCatch-Noro & Quick Navi-Noro 2 & GE test Noro Nissui & Quick Chaser-Noro \\
\hline 12860 & 2 Feb 2015 & $2.50 \times 10^{8}$ & Negative & Negative & Negative & Negative \\
\hline 12868 & 2 Mar 2015 & $8.06 \times 10^{9}$ & Positive & Positive & Positive & Positive \\
\hline 12870 & 4 Mar 2015 & $4.91 \times 10^{3}$ & Negative & Negative & Negative & Negative \\
\hline 12880 & 17 Mar 2015 & $6.46 \times 10^{3}$ & Negative & Negative & Negative & Negative \\
\hline HU-2015 & 31 Jan 2015 & $1.90 \times 10^{9}$ & Positive & Positive & Positive & Positive \\
\hline R1-Thai & 19 Dec 2014 & $1.82 \times 10^{6}$ & Negative & Negative & Negative & Negative \\
\hline
\end{tabular}

a Quantified by real-time RT-PCR (reference values).

GII.4 is the most common infection worldwide and new Gll.4 variants emerge every two to three years [8]. Although based on a small sample size, our findings suggest that the commercial IC kits for the detection norovirus available on the market in Japan are able to detect the novel GII.17 norovirus, but with relatively low sensitivity. Only samples that contained more than $10^{9}$ copies/mL were positive in all four IC tests. Previous data have shown that the minimal detection limit of an IC test for GII.4 norovirus was about $10^{6}$ virus copies/ $\mathrm{mL}$, which is a 1,000-fold more sensitive [9]. Therefore, redesign of the currently available norovirus IC tests may be required to detect the novel GII.17 noroviruses with the same sensitivity as for the more commonly circulating norovirus genotypes. Laboratories and physicians should be aware of these findings, in particular where the novel GII.17 norovirus has been shown to be circulating.

\section{Acknowledgements}

This work was supported by Grants-in-Aid from the Ministry of Education and Sciences and the Ministry of Health, Labor and Welfare, Japan. We are grateful to Dr Shuichi Nishimura, Dr Hideaki Kikuta, Dr.Atsuko Yamamoto, Dr. Kumiko Sugita, Dr Masaaki Kobayashi, and Dr Tsuneyoshi Baba for facilitating specimen collection.

\section{Conflict of interest}

None declared.

\section{Authors' contributions}

PK: conducted the laboratory characterisation of norovirus and drafted the manuscript; AT: conducted the laboratory characterisation of norovirus; ST: involved in laboratory investigation; SO: involved in the data interpretation and revised the manuscript; NM: revised the manuscript; $\mathrm{SH}$ : revised the manuscript; $\mathrm{HU}$ : conceptualised the study and revised the manuscript.

\section{* Authors' correction}

At the request of the authors, reference 9 was replaced on 20 July 2015 .

\section{References *}

1. de Graaf M, van Beek J, Vennema H, Podkolzin AT, Hewitt J, Bucardo F, et al. Emergence of a novel GIl.17 norovirus - End of the GII.4 era? Euro Surveill. 2015;20(26):21178. PMID:26159308

2. Lu J, Sun L, Fang L, Yang F, Mo Y, Lao J, et al. Gastroenteritis Outbreaks Caused by Norovirus GII.17, Guangdong Province, China, 2014-2015. Emerg Infect Dis. 2015;21(7):1240-2. http:// dx.doi.org/10.3201/eid2107.150226 PMID:26080037

3. Fu J, Ai J, Jin M, Jiang C, Zhang J, Shi C, et al. Emergence of a new GII.17 norovirus variant in patients with acute gastroenteritis in Jiangsu, China, September 2014 to March 2015. Euro Surveill. 2015;20(24):21157. PMID:26111236

4. Matsushima Y, Ishikawa M, Shimizu T, Komane A, Kasuo $S$, Shinohara M, et al. Genetic analyses of GII.17 norovirus strains in diarrheal disease outbreaks from December 2014 to March 2015 in Japan reveal a novel polymerase sequence and amino acid substitutions in the capsid region. Euro Surveill. 2015;20(26):21173. PMID:26159307

5. Khamrin P, Thongprachum A, Okitsu S, Maneekarn N, Hayakawa S, Ushijima $\mathrm{H}$. Comparison of three rapid tests for detection of norovirus in stool samples of acute gastroenteritis pediatric patients. J Trop Pediatr. 2014;60(6):481-3. http:// dx.doi.org/10.1093/tropej/fmuo46 PMID:25213738

6. Desselberger U, Goodfellow I. Noroviruses: a global cause of acute gastroenteritis. Lancet Infect Dis. 2014;14(8):6645. http://dx.doi.org/10.1016/S1473-3099(14)70776-5 PMID:24981040

7. Vinjé J. Advances in laboratory methods for detection and typing of norovirus. J Clin Microbiol. 2015;53(2):373-81. http:// dx.doi.org/10.1128/JCM.01535-14 PMID:24989606

8. Thongprachum A, Chan-it W, Khamrin P, Saparpakorn P, Okitsu S, Takanashi S, et al. Molecular epidemiology of norovirus associated with gastroenteritis and emergence of norovirus GII.4 variant 2012 in Japanese pediatric patients. Infect Genet Evol. 2014;23:65-73. http://dx.doi.org/10.1016/j. meegid.2014.01.030 PMID:24508246

9. Takanashi S, Okame M, Shiota T, Takagi M, Yagyu F, Tung PG, et al. Development of a rapid immunochromatographic test for noroviruses genogroups I and II. I Virol Methods. 2008;148(12):1-8.http://dx.doi.org/10.1016/j.jviromet.2007.10.010 PMID:18054091 